\title{
gp120: Good, bad or indifferent?
}

The controversy over a first-generation AIDS vaccine continues to simmer.

In June 1994, the AIDS Research Advisory Committee (ARAC) of the US National Institutes of Health's National Institute of Allergy and Infectious Diseases (NIAID) issued a highly publicized recommendation that a phase III efficacy trial of a controversial preventive AIDS vaccine not go forward "at this time in this country". NIAID Director Anthony Fauci accepted the ARAC recommendation, and placed the trial of the HIV gp120 vaccine (based on a recombinant form of the glycoprotein 120 from the HIV coat) on indefinite hold. Although angered by the decision, the manufacturers of the vaccine, Chiron Biocine and Genentech, have pursued the possibility of performing large trials of the vaccine in Thailand and other countries hit hard by the epidemic, while scientists here continue to argue about the relative merit of gp120. New data from an analysis of people infected after vaccination is raising the pitch of that debate.

The ARAC recommendation was based on two phenomena: the inability of antibodies raised by. the vaccine to neutralize 'primary' or 'field' strains of HIV and a lack of cytotoxic T cell response, and the announcement, just before the ARAC meeting, of several 'breakthrough' infections - phase II trial participants who became infected even though they had received the full course of vaccine immunization. Many observers believe it was the latter that had the most significant influence on the decision.

What do these breakthroughs say about the efficacy of gp120 vaccines? Are they the expected cost of doing a trial, or are they a warning against proceeding further? This question goes to the heart of the debate over vaccines, and even the debate over how to structure clinical vaccine trials. These 'breakthrough' individuals, or at least their blood samples, are now the subject of intense scrutiny, and researchers are preparing to present data from the studies that they say, at the very least, support the Fauci's decision to halt the phase III trials of the vaccine. And although the researchers presenting the data are themselves not drawing further

\section{IMAGE UNAVAILABLE FOR COPYRIGHT REASONS}

conclusions, others who have already seen the data are, and are already beginning to speak out on all sides of the issue.

Different beliefs about the significance of the breakthroughs fall into three loosely defined groups. First there are those, mostly clinical trial researchers, who insist that the numbers under consideration are too small to say anything other than that the gp120 vaccines "are not 100 percent effective," according to Barney Graham of Vanderbilt University, who adds that "it's a very difficult decision [to go forward]." Researchers who agree with Graham about the efficacy argue that even partial effectiveness is helpful, particularly for future vaccine development. "We have been looking at the development of vaccines as a trial-and-error process, with the vaccines getting succeedingly better over time," says Phillip Berman of Genentech. Berman says that much of the debate over gp120 is over its own merit as a final product, rather than as the first step in the 'trial-and-error process'.

Even limited efficacy is an appealing prospect to a country such as Thailand, where HIV infection rates as high as 38 percent in some populations make such efficacy trials more easily performed, and where there is a more desperate need for some form of intervention. Both Chiron (in collaboration with the US Department of Defense) and Genentech are doing preliminary work (phase I trials) en route to a full-scale efficacy trial. "Our operating philosophy is that we are intending to go ahead with trials unless something convinces us otherwise," says Donald Burke of the Walter Reed Army Institute of Research. Burke adds that Chiron is preparing gp120 vaccines based on the predominant types of virus in Thailand, and that the large trial will use a vaccine 들 consisting of a mix of gp120s.

A second group, composed mainly of basic laboratory researchers, insists as adamantly that the vaccines have proved themselves to be of such limited effectiveness - if any - that it would be wiser to shift resources to other avenues of vaccine research. Estimates of the efficacy of the gp120 vaccine vary widely: "Most [estimates] I've heard are between 30 and 50 percent," says June Osborne of the University of Michigan. "No one is saying more than 50 percent." Many believe it is even lower. "If the gp120 vaccines are basically dishwater, and I think that's saying too much for them, then all we're doing is causing a lot of sore arms," says one researcher who declined to be identified. "Everything I know about the performance of the current generation of gp120 subunit vaccines reinforces my belief that Tony Fauci made absolutely the right decision in not approving efficacy trials," says John Moore of the Aaron Diamond AIDS Research Center in New York, and one of the investigators working on the samples from the individuals infected in the phase II trial.

These first two groups were pretty well defined even before the ARAC 
recommendation was made. But now a third group is tentatively going beyond saying that gp120 is ineffective: they are voicing the fear that it may be dangerous. Although it is realistic to expect people to become infected in the course of a clinical trial - that is, after all, intrinsic to the nature of a trial - they argue that someone should be asking why these particular breakthroughs happened. Is it because people believe that, after being vaccinated, they are 'protected' and thus can safely engage in more risky behaviour? If so, that suggests that the current trial protocols have an adverse effect on the control of the epidemic, that is, the limited efficacy of a vaccine may be overcome by the increased risktaking of the vaccinees, underscoring the need for more effective behavioural intervention. They point out that by determining the behaviour of infected trial participants around the time of vaccination it would be possible to determine whether behavioural changes played a role in infection. "It's like DNA evidence: We can't prove that behaviour led to the infection, but we can rule it out if it didn't," said one behavioural researcher who expressed concern about the current structure of vaccine trials.

A more frightening possibility is that there may be a biological basis for the breakthroughs, that is, the vaccine may somehow be enhancing the possibility of infection. This could be a disastrous thing in a country already racked with high infection rates. Researchers who raise this spectre quickly add that there is not strong, or even moderate, evidence for this, but insist that there is enough suggestive data, including the breakthrough infections, to make this a concern that must be addressed. When asked about the possibility, Fauci states emphatically that it is only a theoretical possibility right now, but adds that "it shouldn't be dismissed and it is something that should be looked at." However, he also says that "I think it is taking it a step too far at this point to say that not only doesn't this [gp120 vaccination] help, but it is also bad for you."

The debate over gp120 will likely become more open, more pointed and more loud when the data on the breakthrough infections are fully presented, gaining in intensity as large-scale trials in other countries draw closer.

FINTAN R. STEELE

\section{Courts favour HIV compensation}

Six years after the case began, the Tokyo and Osaka district courts recommended in early October that the Japanese government and five pharmaceutical companies pay $¥ 45$ million (US $\$ 448,000$ ) in compensation to each of 219 haemophiliacs who were infected with the human immunodeficiency virus (HIV) after using contaminated blood products (Nature Medicine 1, 396; 1995). The blood products were imported from the United States during the mid-1980s.

The court's recommendation brings an urgently needed settlement one step nearer to closure for the haemophiliacs (and their families). Ninety-one of the haemophiliacs have already died of AIDS since their cases were first brought in October 1989. They claimed that the government and the pharmaceutical companies were negligent in not acting swiftly enough to approve and supply blood products that had been heattreated to kill the virus.

The courts recommended a settlement plan to the defendants, which urges the

Japanese government and the pharmaceutical companies to accept responsibility and to split the costs. They suggested that the government pays 40 percent of the total compensation package and the five pharmaceutical companies - Green Cross Corporation, Chemo Sero Therapeutic Research Institute, Baxter Limited, Bayer Yakuhin Limited and Nippon Zoki Pharmaceutical Company - pay the rest. The plaintiffs had requested $\$ 1.14$ million in compensation each.

The government is expected to accept the so-called compromise plan, which would enable the plaintiffs to receive compensation quickly, without the government having to acknowledge its legal responsibility in the cases.

Haemophiliacs infected with HIV and their supporters held a rally in Tokyo after the courts announced their decision, where they called on the government and the companies to admit responsibility and to apologize.

RICHARD NATHAN Tokyo

\section{No link between needle exchange programmes and increased drug use}

A major new study has concluded that needle exchange programmes reduce the spread of HIV without increasing illegal drug use, a finding that is likely to put new pressure on the Clinton administration to support federal funding for these efforts.

The study, conducted by a joint panel of the US National Research Council and the Institute of Medicine, recommended that federal funds be made available to communities who seek to establish such programmes. The panel studied the experience of numerous programmes operating in the United States, as well as in Europe, Canada and Australia.

Since 1988, Congress has passed a series of statutes specifically prohibiting or restricting the use of federal funds to support needle exchange programmes. The language of the legislation provides that the ban remain in effect unless the Surgeon General determines that such programmes are effective and do not promote illegal drug use.

Many in the public health community have supported needle exchange programmes, but they are often opposed by

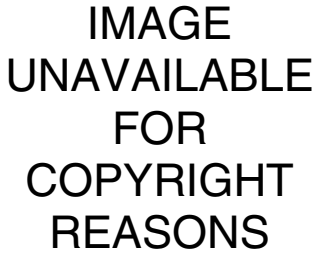

US panel urges federal support of needle exchange programmes to stem spread of HIV.

law enforcement organizations and others who view them as condoning, or even encouraging, illegal drug use.

The panel acknowledged that "the act of giving a needle to an injection drug user has a powerful symbolism that has sparked fears about the potential negative effects of needle exchange programs." However, it added: "There is no credible evidence to date that drug use is increased ... as a result of programs that provide legal access to sterile equipment."

MARLENE CIMONS Washington, $D C$ 